\title{
Cartographic Scale in Immersive Virtual Environments
}

\author{
Florian Hruby ${ }^{1,2}\left(\mathbb{D} \cdot\right.$ Irma Castellanos $^{3}\left(\mathbb{D} \cdot\right.$ Rainer Ress| $^{2}$
}

Received: 2 September 2020 / Accepted: 29 September 2020 / Published online: 12 October 2020

(c) The Author(s) 2020

\begin{abstract}
Scale has been a defining criterion of mapmaking for centuries. However, this criterion is fundamentally questioned by highly immersive virtual reality (VR) systems able to represent geographic environments at a high level of detail and, thus, providing the user with a feeling of being present in VR space. In this paper, we will use the concept of scale as a vehicle for discussing some of the main differences between immersive VR and non-immersive geovisualization products. Based on a short review of diverging meanings of scale we will propose possible approaches to the issue of both spatial and temporal scale in immersive VR. Our considerations shall encourage a more detailed treatment of the specific characteristics of immersive geovisualization to facilitate deeper conceptual integration of immersive and non-immersive visualization in the realm of cartography.
\end{abstract}

Keywords Virtual reality $\cdot$ Scale $\cdot$ Immersion $\cdot$ Immersive virtual environments

\section{Zusammenfassung}

Mittels Anwendungen immersiver virtueller Realität (VR) können geographische Räume so detailgetreu und realistisch nachgebildet werden, dass sich Nutzerinnen und Nutzer in einer solchen virtuellen Umgebung anwesend fühlen. Ein solches räumliches Präsenzerleben gewinnt für die Kartographie insofern an Bedeutung, als diese sich das Ziel setzt, raumbezogenes Wissen durch Repräsentationen zu vermitteln. Wesentliche Bestimmungsmerkmale traditioneller Kartographie, wie zum Beispiel Generalisierung, Symbolisierung oder maßstäbliche Verkleinerung werden jedoch von VR-Systemen grundsätzlich in Frage gestellt und bedürfen seitens der Kartographie einer gründlichen Analyse, um diese rezente Visualisierungstechnologie in das Theorien- und Methodengebäude des Faches eingliedern zu können. Vor diesem Hintergrund versucht der vorliegende Beitrag, einer solchen Integration anhand des kartographischen Schlüsselkonzeptes „Maßstab “ zuzuarbeiten, um immersive und nicht-immersive Geovisualisierungsprodukte mit etabliertem Fachvokabular vergleichbar machen zu können. Nach einer Zusammenfassung wesentlicher Lesarten des Maßstabsbegriffes werden zwei mögliche Sichtweisen auf das Verhältnis von Kartographie und VR vorgestellt, um danach Argumente vorzubringen, warum immersive VR als kartographische Darstellung im sowohl räumlichen als auch zeitlichen Maßstab 1:1 verstanden werden kann.

Schlüsselbegriffe Virtuelle Realität · Maßstab · Immersion · Immersive virtuelle Umgebungen

\section{Introduction}

Florian Hruby

florian.hruby@uni-graz.at

1 Department of Geography and Regional Science, University of Graz, Graz, Austria

2 National Commission for Knowledge and Use of Biodiversity (CONABIO), Mexico City, Mexico

3 Centro de Estudios Estratégicos para el Desarrollo, University of Guadalajara, Guadalajara, Mexico
From a technical perspective, generalization, symbolization and scale have been defining criteria of mapmaking for centuries (Robinson et al. 1995). From an epistemological perspective, these criteria have always been applied to generating insights from geospatial data through graphical representation (MacEachren 2004).

Highly immersive virtual environments (HIVE) represent a fairly new visualization technology beyond these common criteria of cartography (Edler et al. 2018, 2019; 
Tschirschwitz et al. 2019) since geospatial data can be represented in VR at a level of detail that provides the user with a vivid illusion of being there in a virtually mediated environment. Such vivid illusion is frequently referred to as spatial presence in scientific literature, and it has been argued that spatial presence has a positive learning effect (Skarbez et al. 2018; Wirth et al. 2007).

From a hardware perspective, current HIVE rely on stereoscopic depth perception provided by 3D head-mounted displays (HMD) and positional tracking to translate real-world into virtual-world movement and, thus, facilitate interactive exploration of VR space. From a software perspective, game engines (e.g. Unity ${ }^{\circledR}$, Unreal Engine $\left.{ }^{\circledR}\right)$ have become widely used environments for developing HIVE.

In order to distinguish between HIVE in general and those HIVE that represent geographic environments in a realistic (i.e. non-fictitious and non-abstract) manner, we propose to label the latter as geovisualization immersive virtual environments (GeoIVE; cf. Hruby et al. 2019).

The representational power of GeoIVE challenges both cartographic praxis and theory: Practical issues arise, for example, from limited VR-capabilities of geographic information systems (GIS) so that middleware (e.g. game engine software) is required to make GIS data available on a HMD. Theoretical issues result not only from the limited portability of cartographic core concepts, but also in regard to the user. So far, cartography has been visualizing spatial data from outside, i.e. from a third-person perspective, while users experience immersive environments rather from inside, i.e. from a first-person viewpoint.

Here, we will limit our considerations on the question of cartographic scale in immersive virtual environments. To approach this matter from different theoretical viewpoints, several arguments shall be discussed subsequently. Prior to this, the following section shall help to clarify our understanding of scale within this text.

\subsection{On Scale in Cartography}

The concept of scale has been intriguing scholars and scientists for centuries (McMaster and Sheppard 2004). Probably one of the best-known examples of literary considerations on the map-territory relation is Jorge Luis Borges' short story On Exactitude in Science (2004). As also indicated through the title chosen by Borges, scale is-explicitly or implicitly-always about exactitude and, thus, of fundamental interest for geospatial concerns.

Two basic meanings of scale can be distinguished following Goodchild and Proctor (1997). First, scale may refer to the "dimensionless representative fraction" (ibid., p. 21) that describes the mathematical relationship between map space and mapped space, for instance 1:50,000. As argued by Goodchild (2011), the definition of scale as a representative fraction is a child of analogue cartometry, which allows summarizing three properties of each paper map in a single measure, i.e. positional accuracy, spatial resolution and feature content. In digital cartography, these properties are no longer necessarily linked. For instance, one geodatabase may contain features at different levels of detail. Hence, alternative measures of geographic detail have been proposed in recent years (cf. Zhang et al. 2014). Second, scale is used to express the extent of space and time a study is designed for.

One might notice a fundamental difference between both concepts: larger scale will represent smaller portions of a geographic environment in the case of representative fraction, but larger portions in terms of scale-as-extent. According to Zhao and Klippelt (2019; cf. also Montello 2010), we can label the first definition as cartographic scale (in terms of ratio) and the second one as geographic scale (in terms of the extent of a study or a phenomenon). The idea of geographic scale has been already applied to GeoIVE, for instance on spatial knowledge acquisition from different user viewpoints in VR (e.g. ground vs. elevated perspective; Zhao et al. 2020), but little attention has been given to the topic of cartographic scale in virtual space. This paper aims to reduce this gap.

Taken as a ratio, the cartographic scale is a measure to compare geovisualization products with the real-world phenomena they represent. As illustrated in Fig. 1, GeoIVE can reach a level of detail in representation, where virtual and real space become visually almost indistinguishable, so that users can experience the representation of a real place as they would do being physically there.

While cartographers have not made a generally accepted decision on whether and how to apply the term scale to GeoIVE, researches from other disciplines define virtual replicas rather arbitrarily as 1:1 scaled (Combe et al. 2008; Shao et al. 2012), true-to-scale (Peukert et al. 2019; Koller et al. 2019) or full-scale (Pober and Cook 2019) models. Without going into linguistic detail here, we feel that the label 1:1 scaled provides a suitable working definition to describe the relationship between virtual and physical reality as it fits in with cartographic conventions and avoids verbal ambiguity.

\section{Key Questions on Immersive VR and Cartography}

Based on the postulate of a 1:1 scale in GeoIVE, different (incl. conflicting) arguments on the relationship between GeoIVE and non-immersive cartographic visualization can be developed. We will discuss some of the, in our opinion, most significant viewpoints subsequently, thus also shedding some light on the underlying cartographic self-conception. 

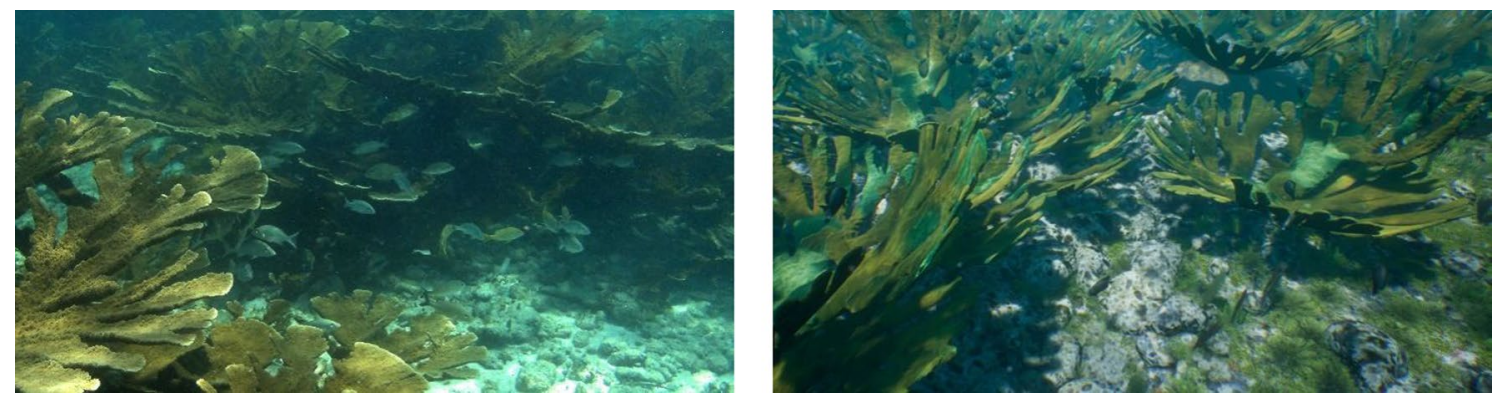

Fig. 1 Virtual or real? 1:1 ration between physical reality (left: photo) and virtual reality (right: render). Example from a Caribbean coral reef

\subsection{Argument 1: Cartography is Not About GeolVE}

GeoIVE can provide highly realistic representations of spatial reality (cf. Fig. 1). This property alone, however, does not make them a cartographic service. Cartography also focuses on the visualization of information implicit to spatial data, while GeoIVE are rather explicit representations in terms of virtual reproductions of real-world places. We can illustrate this argument with the help of a standard method in thematic cartography, namely choropleth mapping. Choropleth maps are considered effective tools for making visible spatial patterns in, usually pre-classified, statistic data. These spatial patterns are taken to evolve on scale levels of 1: $n$ (with $n>1$ ), thus based on the idea of seeing more in terms of the aforementioned concept of scale-as-extent. Although we can visualize statistical data also within VR applications (Marriott et al. 2018), these abstract environments of immersive analytics no longer necessarily address the formation of spatial presence, which we have set as a defining criterion of HIVE.

A similar argumentation could be applied to the usage of aerial images in particular, and photos in general: both accurately represent aspects of reality without being already a cartographic product. In other words, GeoIVE are merely qualitative, while cartography is usually interested in quantitative and quantifiable information. Hence, in terms of argument 1, we should not consider GeoIVE as cartographic representations for the following logical consequence:

1. Maps are scaled down and abstract models of the world.

2. GeoIVE are 1:1 scaled and realistic models of the world.

3. Therefore, GeoIVE cannot be objects of cartographic research.

It should be noted that argument 1 can be taken even a step further: Scale as a representative fraction is an expression of how much a model is down- or up-sized in comparison to the original. In GeoIVE, models are neither down- nor up-scaled. Hence, the concept of scale (in any cartographically relevant sense) could be considered as meaningless so that one might rather speak of unscaled than 1:1 scaled VR environments. In this opinion, premise (2) of the aforementioned argument could be reformulated into "GeoIVE are unscaled and realistic models of the world." However, the argument's conclusion would not be affected by this reformulation.

\subsection{Argument 2: Cartography is Also About GeolVE}

$1: 1$ visualization is a defining characteristic of highly immersive VR-systems, facilitating the acceptance of HIVE in general (Cummings and Bailenson 2016) and GeoIVE in particular (Hruby et al. 2020) as the user's preferred egocentric reference frame (Wirth et al. 2007) and, consequently, the formation of spatial presence, i.e. the feeling of being there in a virtually mediated environment (Skarbez et al. 2018).

A large body of research indicates that the spatial presence perceived within HIVE fosters the user's involvement with the issues visualized, thus leading to higher engagement and deeper understanding compared to non-immersive media (Ahn et al. 2016; Cummings and Bailenson 2016). Since making spatial data understandable has always been a main objective of cartography, GeoIVE can be considered as geovisualization tools par excellence.

However, to maximize benefits from this new technique of representation also for cartographic matters, a broadening of key concepts is required. Regarding scale, we propose to define GeoIVE as three-dimensional 1:1 models, where the user perceives a VR representation of a real place at a level of detail as she would do being physically there. A 1:1 visualization facilitates the acceptance of the GeoIVE as the user's preferred egocentric reference frame and, consequently, the formation of spatial presence.

1. 1:1 scaled GeoIVE facilitate the formation of spatial presence.

2. Spatial presence facilitates understanding.

3. Generating insights from geospatial data through representation is a fundamental objective of cartography.

4. Therefore, GeoIVE are objects of cartographic research. 


\subsubsection{A Matter of Principles}

Although incompatible with each other, both argument 1 and argument 2 are sustained by cartographic textbooks (Robinson et al. 1995; Hake et al. 2002) thus indicating a fundamental discrepancy in the subject's self-conception: On the one hand, cartography aims for explaining geospatial phenomena to the user as effective as possible. On the other hand, generalization, symbolization and scale are considered defining criteria of cartographic representation.

We can now interpret both arguments against this discrepancy: Argument 1 represents a technology-driven approach, which focuses on issues resulting from generalization, symbolization and scale. Argument 2 follows a rather user-driven approach, asking whether geospatial information is communicated differently through GeoIVE vs. nonimmersive mapping products. Regarding a decision between argument 1 and argument 2, we feel that both viewpoints are justifiable on principle. However, accepting argument 1 over argument 2 and excluding GeoIVE a priori from further cartographic considerations seems to be an epistemologically poor decision: On the one hand, recent literature in the realm of cartography shows an increasing interest in GeoIVE from both technical and user-centered viewpoints (Çöltekin et al. 2020; Griffin et al. 2017) so that a thorough analysis of scale in VR could facilitate the integration of GeoIVE into geovisualization workflows and cartographic theory (in terms of argument 2). On the other hand, our understanding of scale will benefit from a critical examination of GeoIVE even if VR technologies would turn out to be of little use for cartographic matters (in terms of argument 1).

Hence, we propose to accept argument 2 over argument 1 at least as a working assumption and, thus, define GeoIVE as cartographic representation products at a 1:1 scale. As several basic considerations on scale in GeoIVE go along with argument 2 we shall mention a few of them subsequently.

\section{Scale in HIVE}

\subsection{Argument 2a: 1:1 Scale in GeolVE is User-Centered}

Both analog and digital mapmaking rely on third-person visualization, where users clearly differentiate between map space and user space and have to bring themselves into a relationship with the information displayed (cf. so-called you-are-here maps (Montello 2010)). This differentiation can be expressed by scales of 1:x (with $x>1$ ).

GeoIVE provide a different approach of conceptualizing the relationship between map space and user space, where users will perceive (through an HMD) just a little difference between VR map space and their own position in physical space (this is, they feel spatially present). Thus, we can distinguish non-immersive third-person cartographies from first-person GeoIVE, where users perceive a VR representation of a real place at a level of detail as they would do being physically there (Hruby 2019).

In technical terms, GeoIVE require dynamical rendering of all objects within the user's range of vision as a function of the distance between object and user. Hence, each VR object not necessarily will be modelled in accordance with a single 1:1 scale level, but rather at different levels of detail (LOD). However, LOD will be exclusively defined by the VR object's distance to the user's position in VR space so that different LODs of the same objects can still be labelled as 1:1 scaled: at close range, users will see a VR object at high resolution while perceiving a lower resolution from far. Both high- and low-resolution objects can be defined as 1:1 models, as they represent the object as the user would perceive it from a given position in VR space.

To sum up this thesis on user-centered scale, we can argue that a non-immersive (2D) map renders all map objects at a single distance with a single scale. Hence, equal objects are visualized equally. In HIVE, the user perceives objects from different distances so that equal objects are rendered differently as a function of distance. Nevertheless, these differently rendered objects maintain a single, yet dynamic scale of $1: 1$, i.e. users perceive them differently from different distances as they would do being really there.

\subsection{Argument 2b: 1:1 Scale in GeolVE is Spatio-Temporal}

Users' ability to interact with and move around within VRspace is a defining criterion of HIVE. Since movement is the change in position over time, scale in GeoIVE cannot be reduced to its spatial dimension. Cartographers concern themselves with time rather as a feature of geospatial data, which allows for analyzing and describing change (e.g. of land cover) through (mostly) static maps. Static maps can, of course, visualize one or several points in time, but do not show any particular temporal scale (at least not in terms of scale as representative fraction). Using time as a variable of mapping change, i.e. visualizing time through time through animation (Battersby and Goldsberry 2010; Harrower and Fabrikant 2008), seems to be a rather secondary issue on the cartographic research agenda. Regarding dynamic maps (in terms of cartographic animations of geospatial change over time), the two basic understandings of cartographic vs. geographic scale (cf. Sect. 2) apply.

By definition, GeoIVE represent both space and time at a 1:1 scale level. We already defined the spatial 1:1 scale as a visualization scenario, where the user perceives VR space in analogy to real space. Accordingly, the temporal 1:1 scale means to experience change over time in a GeoIVE as one 
would do being physically there in the real world referent. Hence, we can consider temporal 1:1 scaled GeoIVE as a kind of real-time visualization. In analogy to the relation of virtual reality and physical reality, we can describe the temporal scale of GeoIVE as virtual real-time. This means, for example, that within an immersive VR coral reef you cannot see what is currently happening in the corresponding real-world coral reef (at least at the current state of the art). However, you can see in VR what currently could be happening in physical reality.

It thus seems to be appropriate to differentiate not just between virtual reality and physical reality in a spatial sense, but also between real-time and virtual real-time as well as between real simultaneousness and virtual real simultaneousness. Since one second takes one second in both realtime and virtual real-time, we propose to describe this relationship as a temporal 1:1 scale.

Finally, it should be noted that the user not necessarily has to be the only mobile agent interacting with the VR environment. Other actors can also be considered regarding their movement and even behavior (e.g. animals) in terms of the aforementioned dynamic 1:1 scale.

\section{Discussion and Conclusion}

In this paper, we used scale as a vehicle for analyzing some basic characteristics of HIVE when applied to geovisualization matters. It became apparent that immersive environments question not only cartographic core concepts like scale, but also, e.g. generalization and symbolization on principle. Moreover, as we have tried to argue, we cannot reduce the meaning of scale to its spatial dimension. GeoIVE have to be considered 1:1 scaled in both temporal and spatial regards. Consequently, a thorough discussion of VR space has to consider also the concept of VR time and temporal scale.

GeoIVE necessarily bring the user from the third-person perspective of common maps to a first-person viewpoint, thus converting space into place (cf. Seamon and Sowers 2008). This change in perspective takes effect on different levels: 1: $x$ scaled maps can be measured on a topographic information level (e.g. the distance between two species on a tree map) but not on an icon-based level (e.g. you cannot deduce the diameter of a real tree from the accordant map symbol as a mere function of scale). In GeoIVE, by contrast, abstract map icons turn into realistic 1:1 replicas you can evaluate concerning individual characteristics as you would do being really there (e.g. regarding size, diameter, and species of a given tree). It is important to emphasize that 1:1 scaled objects and agents of a GeoIVE not necessarily set aside symbolization and generalization, which could be approached from a prototype theory perspective (Taylor 2003; Zhang 2020), for example (Fig. 2).

In order to combine the benefits of both 1:x maps and 1:1 GeoIVE, maps can be implemented into the VR space and perceived within the virtual environment (Fig. 3). Further research will be necessary to better understand cognitive implications of mixed first- and third-person visualization (e.g. with respect to navigation and memorization tasks, but also concerning spatial presence), and the human-computer interaction with artefacts in VR space (e.g. usage of 2D-maps within an immersive 3D-environment).

Scale is a parameter of fundamental importance for geovisualization and defines the spatial patterns we can visualize, recognize, and analyze (Buttenfield 1989; Suárez-Seoane and Baudry 2002). GeoIVE broaden the scale spectrum available for cartographic representation, thus expanding the mapmaker's repertoire of visualization tools significantly.

Even the narrow focus on issues on scale we have taken along this text has shown that immersive VR systems not only question cartography's self-conception. Rather, GeoIVE could provide several intra- (e.g. with multimedia cartography) and interdisciplinary links (e.g. on spatial cognition and artificial intelligence in HIVE) for future research. As we tried to show by way of argument, the consideration of GeoIVE as a cartographic method of visualization can be approved or rejected. Whatever position one might take concerning this matter, a thorough discussion of different (incl. opposite) positions can only strengthen our understanding of scale in cartography.

Comparing non-immersive (1: $x$ scaled) versus highimmersive (1:1 scaled) geovisualization products, we can observe, once again, how the weak points of one approach
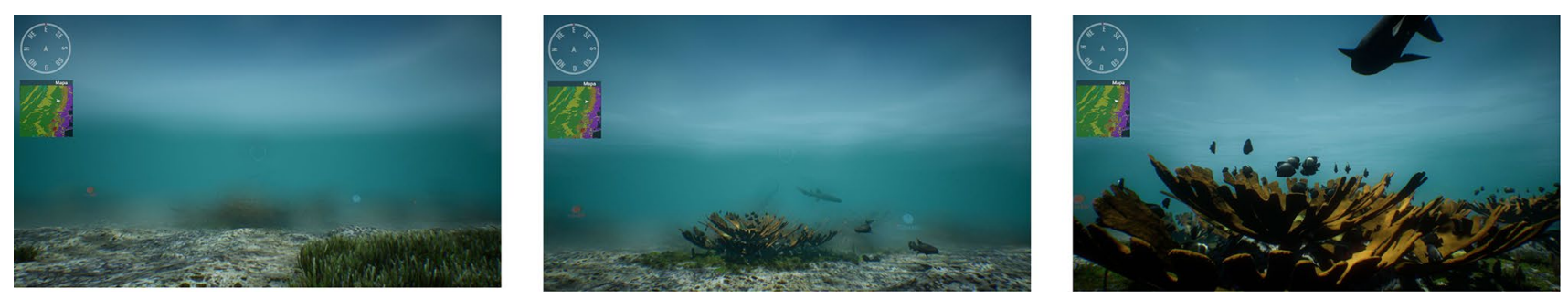

Fig. 2 User-centered dynamic 1:1 scales of an elkhorn coral (Agropora palmata) colony in a HIVE 


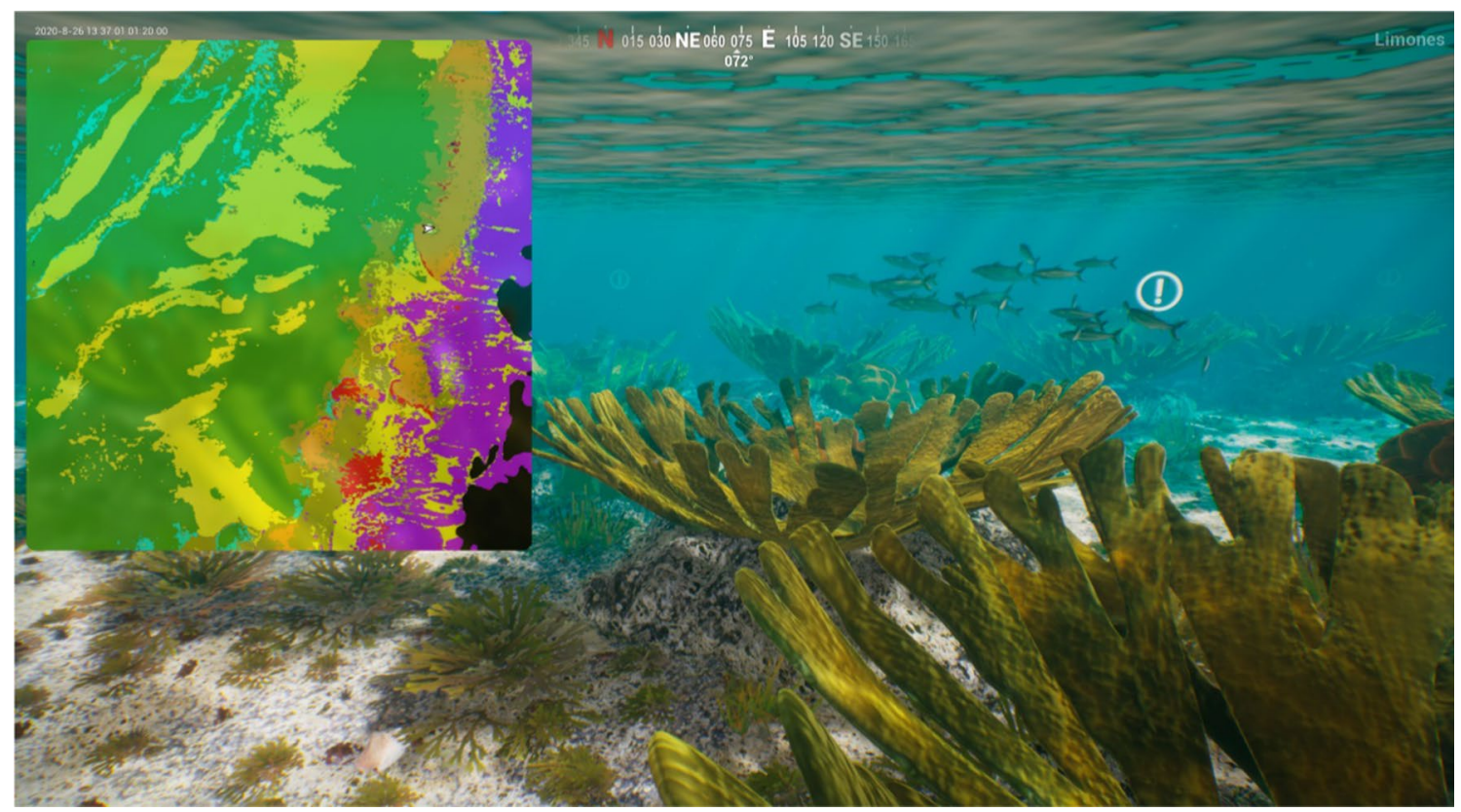

Fig. 3 Combining (map-based) third-person representation and first-person visualization within GeoIVE

can be the strengths of an alternative technique. Cartographers have already argued for a multi-representational viewpoint on geovisualization (MacEachren 2004), in order to provide the users with "different maps presenting a range of both plausible and extreme cartographic views." (Monmonier 1991, p. 4). Within this scope of "different maps", GeoIVE provide a new visualization technique that is possibly extreme, but definitely plausible and expands cartographic representation towards what we proposed here to call a 1:1 scale level.

\subsection{Final Note}

Due to the publication format of this paper, we approached scale in immersive VR only in a non-immersive manner. In addition to the bibliography below, interested readers are referred to the following GeoIVE application (https://tinyu rl.com/geoive), which may serve not only to experience the feeling of being there but also provide some test material for further studies on scale in GeoIVE.

Funding Open access funding provided by University of Graz.

Open Access This article is licensed under a Creative Commons Attribution 4.0 International License, which permits use, sharing, adaptation, distribution and reproduction in any medium or format, as long as you give appropriate credit to the original author(s) and the source, provide a link to the Creative Commons licence, and indicate if changes were made. The images or other third party material in this article are included in the article's Creative Commons licence, unless indicated otherwise in a credit line to the material. If material is not included in the article's Creative Commons licence and your intended use is not permitted by statutory regulation or exceeds the permitted use, you will need to obtain permission directly from the copyright holder. To view a copy of this licence, visit http://creativecommons.org/licenses/by/4.0/.

\section{References}

Ahn SJ, Bostick J, Ogle E, Nowak KL, McGillicuddy KT, Bailenson JN (2016) Experiencing nature: embodying animals in immersive virtual environments increases inclusion of nature in self and involvement with nature. J Comput-Med Commun 21(6):399-419

Battersby SE, Goldsberry KP (2010) Considerations in design of transition behaviors for dynamic thematic maps. Cartogr Perspect 65:16-32

Borges J (2004) On exactitude in science. In: Borges JA (ed) Universal history of iniquity. Penguin Books, London

Buttenfield BP (1989) Scale-dependence and self-similarity in cartographic lines. Cartographica 26(1):79-100

Çöltekin A et al (2020) Extended reality in spatial sciences: a review of research challenges and future directions. ISPRS Int J Geo-Inf 9(7):439

Combe E, Posselt J, Kemeny A (2008) 1: 1 Scale perception in virtual and augmented reality. In: 18th international conference on artificial reality and telexistence, pp 152-160

Cummings JJ, Bailenson JN (2016) How immersive is enough? A meta-analysis of the effect of immersive technology on user presence. Media Psychol 19(2):272-309

Edler D, Husar A, Keil J, Vetter M, Dickmann F (2018) Virtual reality (VR) and open source software: a workflow for constructing an interactive cartographic VR environment to explore urban landscapes. Kartographische Nachrichten 68(1):3-11

Edler D, Keil J, Wiedenlübbert T, Sossna M, Kühne O, Dickmann F (2019) Immersive VR experience of redeveloped post-industrial sites: the example of "Zeche Holland" in Bochum-Wattenscheid. KN-J Cartogr Geogr Inf 69(4):267-284 
Goodchild MF (2011) Scale in GIS: an overview. Geomorphology 130(1-2):5-9

Goodchild MF, Proctor J (1997) Scale in a digital geographic world. Geogr Environ Model 1:5-24

Griffin AL et al (2017) Designing across map use contexts: a research agenda. Int J Cartogr 3(sup1):90-114

Hake G, Grünreich D, Meng L (2002) Kartographie. Walter de Gruyter, Berlin

Harrower M, Fabrikant SI (2008) The role of map animation in geographic visualization. In: Dodge $\mathrm{M}$, et al. (eds) Geographic visualization: concepts, tools and applications. Wiley, Chichester, pp 49-65

Hruby F (2019) From third-person to first-person cartographies with immersive virtual environments. Proc Int Cartogr Assoc 2:44

Hruby F, Ressl R, la Borbolla De, del Valle G (2019) Geovisualization with immersive virtual environments in theory and practice. Int $\mathrm{J}$ Dig Earth 12(2):123-136

Hruby F, Álvarez Sánchez LF, Ressl R, Escobar-Briones EG (2020) An Empirical study on spatial presence in immersive geo-environments. PFG J Photogrammetry Rem Sens Geoinform Sci 88:155-163

Koller S, Ebert LC, Martinez RM, Sieberth T (2019) Using virtual reality for forensic examinations of injuries. Forensic Sci Int 295:30-35

MacEachren AM (2004) How maps work: representation, visualization, and design. Guilford Press, New York, London

Marriott K, et al. (eds) (2018) Immersive Analytics. Springer, Cham

McMaster RM, Sheppard E (2004) Introduction: scale and geographic inquiry. In: Sheppard E, McMaster RM (eds) Scale geographic. Blackwell, Oxford, pp 1-22

Monmonier M (1991) Ethics and map design: Six strategies for confronting the traditional one-map solution. Cartogr Perspect 10:3-8

Montello DR (2010) You are where? The function and frustration of you-are-here (YAH) maps. Spatial Cogn Comput 10(2-3):94-104

Peukert C, Pfeiffer J, Meißner M, Pfeiffer T, Weinhardt C (2019) Shopping in virtual reality stores: the influence of immersion on system adoption. J Manag Inf Syst 36(3):755-788
Pober E, Cook M (2019) Thinking in virtual spaces: impacts of virtual reality on the undergraduate interior design process. Int J Virtu Augmented Real 3(2):23-40

Robinson AH, Morrison JL, Muehrcke PC, Kimerling AJ, Guptill SC (1995) Elements of cartography. Wiley, New York

Seamon D, Sowers J (2008) Place and placelessness. In: Hubbard P, Kitchen R, Vallentine G (eds) Key texts in human geography. Sage, London, pp 43-52

Shao F, Robotham AJ, Hon KK (2012) Development of a 1: 1 Scale true perception virtual reality system for design review in automotive industry. In: 10th international conference on manufacturing research, pp 468-473

Skarbez R, Brooks FP Jr, Whitton MC (2018) A survey of presence and related concepts. ACM Comput Surv (CSUR) 50(6):96

Suárez-Seoane S, Baudry J (2002) Scale dependence of spatial patterns and cartography on the detection of landscape change: relationships with species' perception. Ecography 25(4):499-511

Taylor JR (2003) Linguistic categorization. Oxford University Press, Oxford

Tschirschwitz F, Richerzhagen C, Przybilla HJ, Kersten TP (2019) Duisburg 1566: transferring a historic $3 \mathrm{~d}$ city model from google earth into a virtual reality application. PFG J Photogram Remote Sens Geoinf Sci 87(1-2):47-56

Wirth W et al (2007) A process model of the formation of spatial presence experiences. Media Psychol 9(3):493-525

Zhang G (2020) Design of virtual reality augmented reality mobile platform and game user behavior monitoring using deep learning. Int J Electr Eng Educ. https://doi.org/10.1177/0020720920931079

Zhang J, Atkinson P, Goodchild MF (2014) Scale in spatial information and analysis. CRC Press, Boca Ratón

Zhao J, Klippelt A (2019) Scale-unexplored opportunities for immersive technologies in place-based learning. In: IEEE conference on virtual reality and 3D user interfaces, pp 155-162

Zhao J, Simpson M, Wallgrün JO, Sajjadi P, Klippel A (2020) Exploring the effects of geographic scale on spatial learning. Cogn Res Princ Implicat 5:1-18 